\title{
Transvaginal Hybrid NOTES Cholecystectomy: Current Techniques and Advantages
}

\author{
Juan S. Barajas-Gamboa • Garth R. Jacobsen
}

Published online: 16 October 2013

(C) Springer Science + Business Media New York 2013

\begin{abstract}
Laparoscopic cholecystectomy has proven to be a safe and effective procedure, with low rates of complications and mortality since its introduction in the late 1980s. However, surgeons have been working to develop alternatives to this technique to improve clinical outcomes and the level of patient satisfaction. Natural orifice transluminal endoscopic surgery (NOTES) is one such alternative. NOTES has potential benefits compared to conventional laparoscopic and open surgery, including reduced abdominal wall trauma and trocar site complications, lower infection rates, less postoperative pain, decreased hospital stays, and excellent cosmetic results. Transvaginal hybrid NOTES cholecystectomy is the most common NOTES procedure performed. The objective of this article is to review this surgical technique and its clinical outcomes based on the current scientific evidence available in the literature.
\end{abstract}

Keywords NOTES - Natural orifice · Cholecystectomy · Transvaginal $\cdot$ Hybrid

\section{Introduction}

Since its introduction in the late 1980s, laparoscopic cholecystectomy (LC) has been a common surgical procedure worldwide that is relatively straightforward and safe with low rates of complications and mortality [1]. This approach has been widely accepted and adopted by surgeons during

J. S. Barajas-Gamboa · G. R. Jacobsen $(\bowtie)$

Center for the Future of Surgery, Division of Minimally Invasive

Surgery, Department of Surgery, University of California San

Diego, 9500 Gilman Drive \#0740, La Jolla, CA 92093, USA

e-mail: gjacobsen@ucsd.edu the last decades $[2,3 \cdot \bullet, 4,5]$. However, with the evolution minimally invasive surgery (MIS) techniques, surgeons have been working to develop alternatives to this technique to improve clinical outcomes and the level of satisfaction postoperatively $[6,7 \bullet, 8,9,10 \bullet 11]$.

One viable option currently being explored is natural orifice transluminal endoscopic surgery (NOTES) [12••, 13-17]. This concept was initially designed to access the abdominal cavity through different natural orifices such as the mouth, vagina, anus, and urethra $[9,18,19]$. In addition, several studies have shown applications in intrathoracic procedures including mediastinoscopy, thoracoscopy, and lymph node dissection [14, 19, 20].

NOTES has potential benefits compared to conventional laparoscopic and open surgery, including reduced abdominal wall trauma and trocar site complications, low infection rates, less postoperative pain, decreased hospital stays, and excellent cosmetic results $[3 \cdot \bullet, 9,11,13,21]$. Furthermore, NOTES procedures can be performed using a transabdominal needle or laparoscopic instruments (i.e. "Hybrid NOTES") or not using any extra instrument (i.e. "Pure NOTES") [7, 22•, 23-25].

Transvaginal hybrid NOTES cholecystectomy (THNC) is the most common NOTES procedure performed [2, 10, 23, 24, 26]. In 1993, the first successful THNC was described by Delvaux et al. [27], followed by Marescaux et al. [28], who reported the first successful transvaginal pure NOTES cholecystectomy (TPNC) in humans in 2007.

Despite the increased number of clinical studies confirming the advantages and benefits of THNC $[4,8,12 \cdot \bullet$, $21,22 \cdot, 29]$, it is still considered an investigational surgical approach in many aspects, and surgeons still have concerns regarding the safety of this procedure in terms of sexual function and future fertility [30-33, 34•, 35]. The objective of this article is to review this surgical technique and its 
clinical outcomes based on the current scientific evidence available in the literature.

\section{Patient Selection (Preoperative Evaluation)}

Several groups have attempted to standardize patient selection criteria for THNC in order to achieve safe and effective clinical outcomes [4, 14, 18, 36, 37]. However, there is not an official consensus defining these criteria. In our institution, candidates for THNC are treated in the same fashion as candidates for standard laparoscopic cholecystectomy. We adhere to the SAGES/NOSCAR standards in preoperative evaluation, and all patients undergo rigorous workup prior to undergoing THNC [38••].

In short, patients are evaluated at the clinic by the attending surgeon. Patients have a complete physical exam and medical history evaluation. Routine radiological evaluation including abdominal ultrasound and computed tomography scan (CT scan) are performed. A pelvic exam is also performed to rule out any anatomic contraindications to the procedure. Laboratory studies are performed as indicated and a human chorionic gonadotropin urine assay must be negative prior to surgery.

Patients with any of the following existing conditions may be excluded for this approach: (1) pregnancy, (2) morbid obesity (BMI $\geq 35 \mathrm{~kg} / \mathrm{m}$ [2]), (3) presence of severe medical comorbidities (ASA of 2 or below), (4) gallbladder masses, or tumor, (5) history of prior open abdominal or transvaginal surgery, (6) prior history of peritoneal or vaginal trauma, (7) history of ectopic pregnancy, pelvic inflammatory disease, or severe endometriosis, (8) known common bile duct stones, (9) patients on anticoagulants, antiplatelet drugs, or with abnormal blood coagulation tests, and (10) immunocompromised patients.

\section{Surgical Technique}

After all inclusion and exclusion criteria are met, the candidate is brought to the operating room. Each patient receives appropriate pharmacologic deep venous thrombosis prophylaxis and prophylactic antibiotics. As in all operations, preparation of the operating room and patient positioning are critical. The abdomen is prepped in the standard fashion for a laparoscopic cholecystectomy using chlorhexidine solution. The perineal region is prepped using betadine solution. Both areas are draped in a standard sterile fashion, and a Foley catheter is placed [29].

The first incision is placed in the umbilicus with a scalpel to permit the entry of a 5-mm port under laparoscopic visualization. Pneumoperitoneum is created to $15 \mathrm{mmHg}$. A 30-degree laparoscope is inserted to visualize the abdominal cavity and assess the gallbladder. If there is any evidence of dense inflammatory response in the pelvis or right upper quadrant, or any intra-abdominal pathology that could potentially compromise the safety of the operation, standard laparoscopic technique is used and the NOTES technique is aborted [39].

Next, the uterus is elevated by using a uterine manipulator (Fig. 1). A 12-mm port is inserted bluntly through the posterior vaginal wall (Fig. 2). The laparoscopic view is then changed to an endoscopic view. If necessary, an Endograb device (Virtual Ports, Richmond, VA, USA) is inserted through the umbilicus into the peritoneal cavity and positioned to grasp the fundus and secure it to the anterior abdominal wall to expose the target anatomy (Fig. 3). There is liberal use of the umbilical access port in dissection of the gallbladder, as well as to expose the cystic artery and cystic duct (Fig. 4). After obtaining a definitive critical view, and confirming this view with a standard 30-degree laparoscope placed through the umbilicus, the cystic artery and then the duct are triply clipped and divided. The gallbladder is taken off the hepatic bed using electrocautery or ultrasonic dissection. Complete hemostasis is ensured. A 30-degree laparoscope is again inserted through the umbilicus and the endoscope in the vagina is exchanged for a retrieval bag [22•].

The gallbladder is placed in the bag and removed from the vagina (Fig. 5). Laparoscopic instruments are removed, and the abdomen is desufflated. Before closing the vaginotomy, the umbilical port is infiltrated using $0.5 \%$ bupivacaine. Finally, the vaginotomy is closed under direct vision using absorbable suture.

\section{Postoperative Care and Follow up}

Post-operatively, patients are treated under the same standard of care as a laparoscopic cholecystectomy.

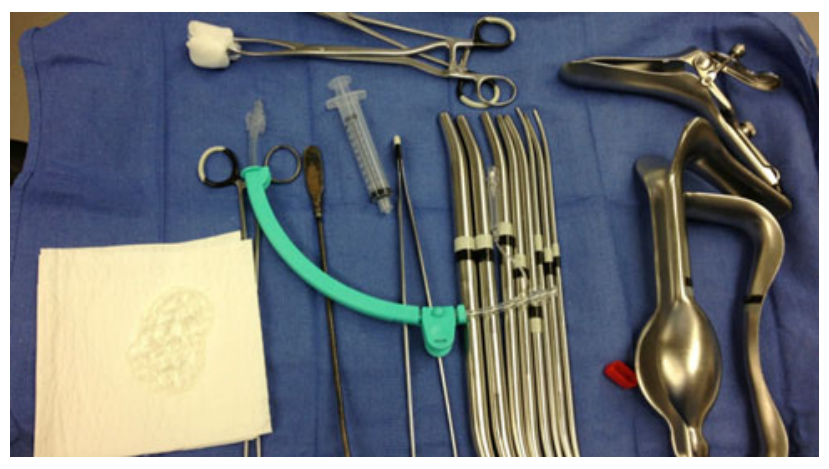

Fig. 1 Transvaginal trocar placement instruments set 

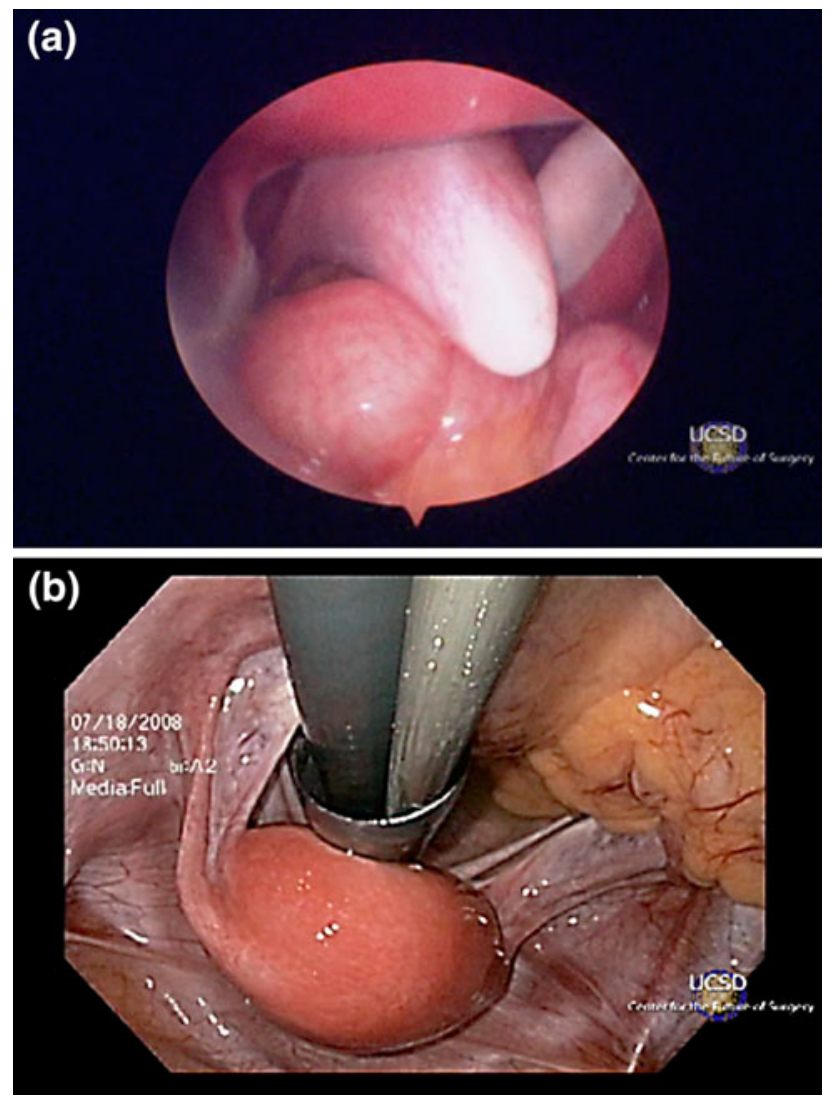

Fig. 2 Transvaginal entrance

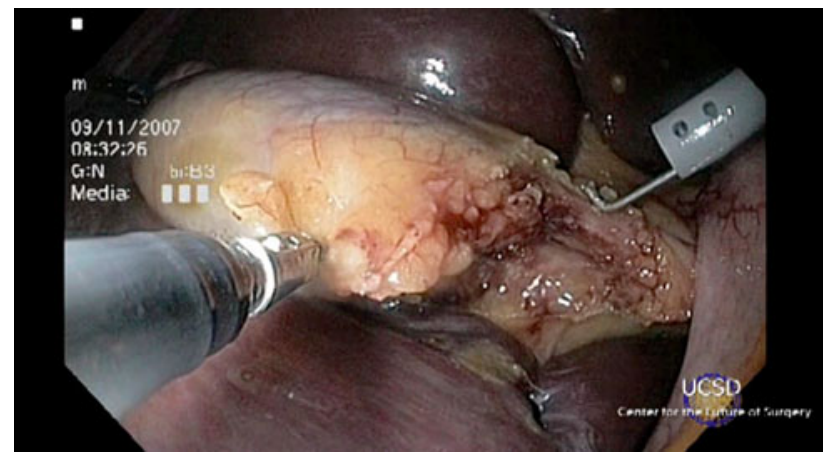

Fig. 3 Cystic duct exposed

Patients are discharged from the hospital when they can tolerate a liquid diet, are adequately mobile, and their pain is well controlled. Upon discharge, patients are instructed to recognize potential postoperative complications and/or alarms (signs and symptoms) related to this procedure. Patients are recommended to avoid sexual intercourse during the first month after surgery. Furthermore, patients are evaluated in clinic at 1 week postoperatively, and by phone at 6 months and 1 year postoperatively (Fig. 6).

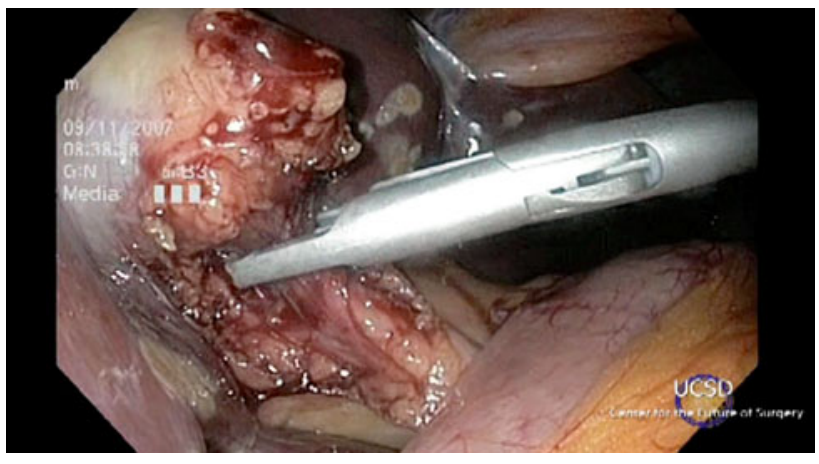

Fig. 4 Cystic artery and duct clipped and divided

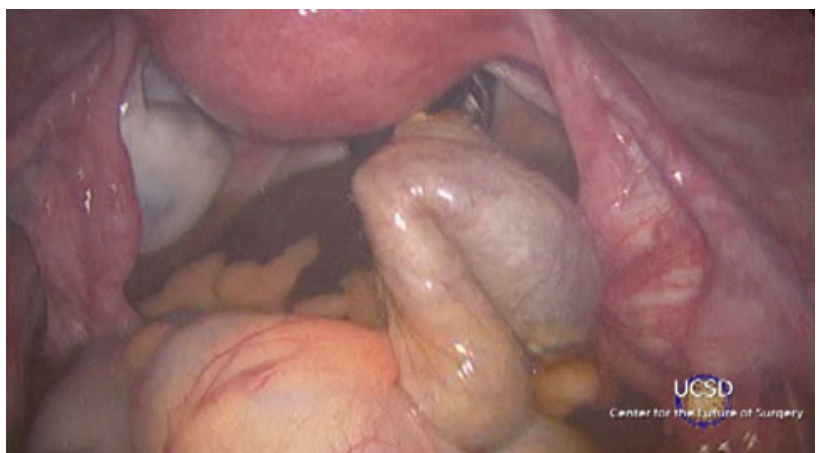

Fig. 5 Dissected gallbladder during its removal

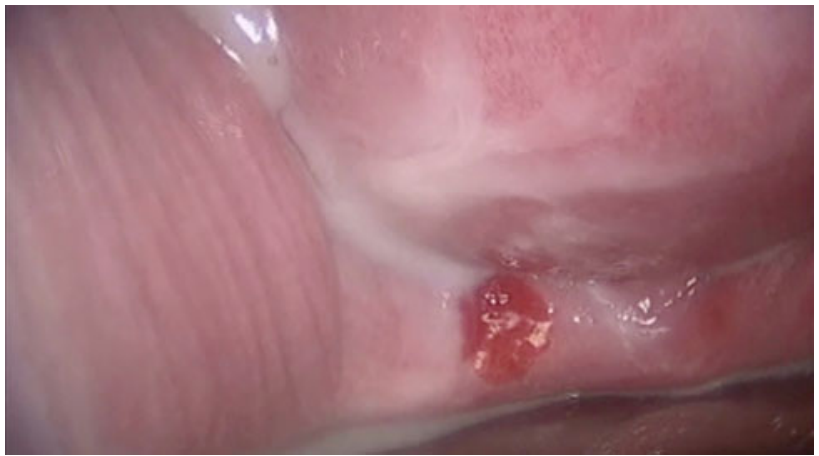

Fig. 6 Trocar incision 7 days postoperatively

\section{Literature Search}

A medical literature search was conducted using PubMed, attempting to find publications available describing human NOTES cholecystectomies in clinical studies from January 1, 1993 to April 15, 2013. In this search, keywords included "Natural orifice transluminal endoscopic surgery", "Minimally invasive surgery", "Cholecystectomy", "Transvaginal approach", "Surgical procedure", "Review" and "Clinical trials". Non-English language 


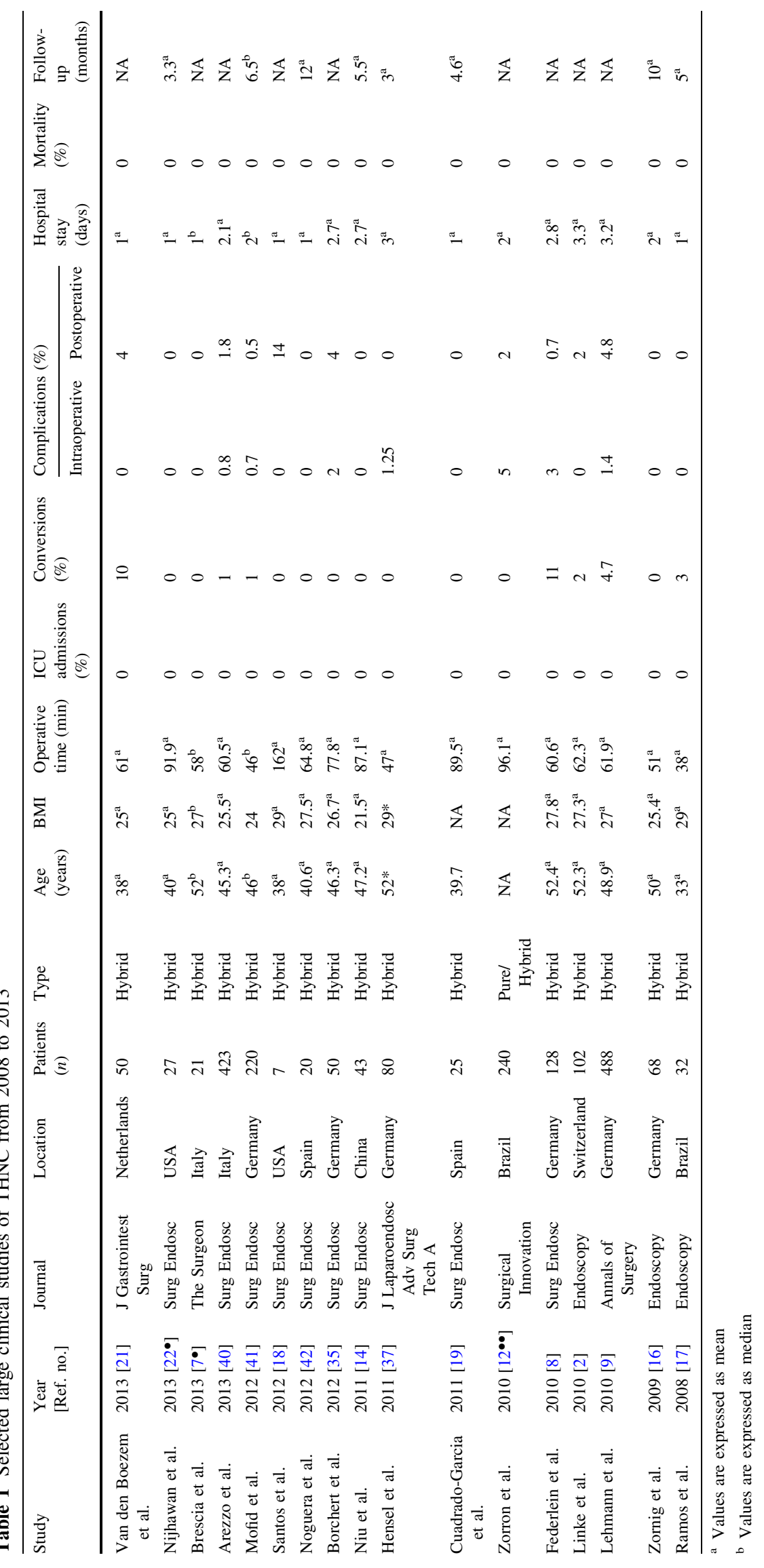


manuscripts were excluded from this search to expedite the review process. There was no limitation to the level of evidence of these studies that were evaluated. A total of 150 articles were found in PubMed using the search terms listed above. Of this 150, 77 were considered relevant to review by authors and 33 were selected for detailed further review.

\section{Clinical Outcomes}

Arezzo et al. published a 2-year activity report from the EURO-NOTES clinical registry describing 423 THNC cases. The mean age was 45.3 years (range 16-76) and the average body mass index (BMI) was 25.3 (range 16-50). All patients had an American Society of Anesthesiology (ASA) classification of 2 or below [40].

Horgan et al. reported 48 THNC cases with a mean operative time of $89.8 \mathrm{~min}$ (range 38-165). Conversions to an open or laparoscopic operation and intraoperative complications were not found, and all the procedures were successfully completed. No patients required admission to an intensive care unit in this study. In the follow-up period, there were three pregnancies and an equal number of successful vaginal deliveries [39].

Mofid et al. published 220 THNC cases with a median hospital stay of 2 days. Patients were followed for a median of 6.5 months. The only intraoperative complication was a puncture of the urine bladder. Two postoperative complications were observed: one biliary fistula 3 days after THNC, and one abscess in the Douglas pouch 3 weeks after THNC. There were no trocar site complications and the mortality rate in this study was $0 \%$ [41].

Noguera et al. evaluated postoperative pain in 20 THNC cases. Using a visual analog scale (VAS), postoperative pain was assessed after surgery on postoperative evaluations on days 1, 7, and 30, and months 6 and 12. The median pain scores were $3.94,2.52,0.73,0.36$, and 0.10 , respectively. This pain was very well controlled by the standard oral narcotic pain medications [42].

Linke et al. published a prospective single-center cohort study investigating sexual function, patient satisfaction, and quality of life in sexually active women 1 year after THNC. A total of 106 patients participated in this study. Patient satisfaction was assessed 1 year after surgery with the validated version of the female sexual function index (FSFI-D). Sexual life impartment and quality of life were assessed by the gastrointestinal quality of life index (GIQLI) prior and 1 year after surgery. FSFI-D total scores showed that 84 out of 88 patients $(95 \%)$ were satisfied with THNC. Sexual life significantly improved (GIQLI scores $3.2 \pm 1.0$ pre surgery vs. $3.7 \pm 0.71$ year postoperatively, $P<0.001$ ) and painful sexual intercourse
$(3.3 \pm 1.0$ vs. $3.6 \pm 0.7, P=0.008)$ decreased post-surgery [34•]. Preoperative parameters and postoperative outcomes of selected large published clinical studies from 2008 to 2013 are summarized on (Table 1).

\section{Conclusions}

THNC is a safe and feasible surgical approach that suggests superior clinical outcomes compared with the standard laparoscopic cholecystectomy in terms of improved cosmetic results, decreased rates of trocar site complications, shorter hospital stay, less postoperative pain, and reduced use of pain medications. Current clinical evidence has not found relevant impacts on sexual function and future fertility. Given this promising data, this surgical approach may prove to be a superior mode of gallbladder removal in female patients. Further randomized studies and long-term follow-up are needed to determine if this procedure will play a major role in the daily clinical practice.

\section{Compliance with Ethics Guidelines}

Conflict of Interest Garth R. Jacobsen has received honoraria for serving as a consultant and has received payment for development of educational presentations including service on speakers' bureaus) from Ethicon Endo Surgery. Juan S. Barajas-Gamboa declares that he has no conflict of interest.

Human and Animal Rights and Informed Consent This article does not contain any studies with human or animal subjects performed by any of the authors.

\section{References}

Papers of particular interest, published recently, have been highlighted as:

- Of importance

- Of major importance

1. Ross S, Rosemurgy A, Albrink M, et al. Consensus statement of the consortium for LESS cholecystectomy. Surg Endosc. 2012;26:2711-6.

2. Linke GR, Tarantino I, Hoetzel R, et al. Transvaginal rigidhybrid NOTES cholecystectomy: evaluation in routine clinical practice. Endoscopy. 2010;42:571-5.

3. • Fuchs KH, Meining A, von Renteln D, et al. Euro-NOTES status paper: from the concept to clinical practice. Surg Endosc. 2013;27:1456-67. This paper presents the experience of the European NOTES Consortium.

4. Bulian DR, Trump L, Knuth J, Cerasani N, Heiss MM. Long-term results of transvaginal/transumbilical versus classical laparoscopic cholecystectomy-an analysis of 88 patients. Langenbecks Arch Surg. 2013;398:571-9.

5. Markar SR, Karthikesalingam A, Thrumurthy S, Muirhead L, Kinross J, Paraskeva P. Single-incision laparoscopic surgery (SILS) vs. conventional multiport cholecystectomy: systematic review and meta-analysis. Surg Endosc. 2012;26:1205-13. 
6. Clark MP, Qayed ES, Kooby DA, Maithel SK, Willingham FF. Natural orifice translumenal endoscopic surgery in humans: a review. Minim Invasive Surg. 2012;2012:189296.

7. - Brescia A, Masoni L, Gasparrini M, et al. Laparoscopic assisted transvaginal cholecystectomy: single centre preliminary experience. Surgeon. 2013;11 Suppl 1:S1-5. This publication shows the benefits of this technique in a large series of patients; this research evidence was released recently this year.

8. Federlein M, Borchert D, Muller V, et al. Transvaginal videoassisted cholecystectomy in clinical practice. Surg Endosc. 2010;24:2444-52.

9. Lehmann KS, Ritz JP, Wibmer A, et al. The German registry for natural orifice translumenal endoscopic surgery: report of the first 551 patients. Ann Surg. 2010;252:263-70.

10. - Horgan S, Thompson K, Talamini M, et al. Clinical experience with a multifunctional, flexible surgery system for endolumenal, single-port, and NOTES procedures. Surg Endosc. 2011;25:586-92. This paper represents one of the first reports of NOTES using flexible surgery systems and single port systems.

11. Coomber RS, Sodergren MH, Clark J, Teare J, Yang GZ, Darzi A. Natural orifice translumenal endoscopic surgery applications in clinical practice. World J Gastrointest Endosc. 2012;4:65-74.

12. • Zorron R, Palanivelu C, Galvao Neto MP, et al. International multicenter trial on clinical natural orifice surgery-NOTES IMTN study: preliminary results of 362 patients. Surg Innov. 2010;17:142-58. This publication is one of the few international multicenter trials on NOTES.

13. Auyang ED, Santos BF, Enter DH, Hungness ES, Soper NJ. Natural orifice translumenal endoscopic surgery $\left(\right.$ NOTES $^{\circledR}$ ): a technical review. Surg Endosc. 2011;25:3135-48.

14. Niu J, Song W, Yan M, et al. Transvaginal laparoscopically assisted endoscopic cholecystectomy: preliminary clinical results for a series of 43 cases in China. Surg Endosc. 2011;25:1281-6.

15. Huang C, Huang RX, Qiu ZJ. Natural orifice transluminal endoscopic surgery: new minimally invasive surgery come of age. World J Gastroenterol. 2011;17:4382-8.

16. Zornig C, Mofid H, Siemssen L, et al. Transvaginal NOTES hybrid cholecystectomy: feasibility results in 68 cases with midterm follow-up. Endoscopy. 2009;41:391-4.

17. Ramos AC, Murakami A, Galvao Neto M, et al. NOTES transvaginal video-assisted cholecystectomy: first series. Endoscopy. 2008;40:572-5.

18. Santos BF, Teitelbaum EN, Arafat FO, Milad MP, Soper NJ, Hungness ES. Comparison of short-term outcomes between transvaginal hybrid NOTES cholecystectomy and laparoscopic cholecystectomy. Surg Endosc. 2012;26:3058-66.

19. Cuadrado-Garcia A, Noguera JF, Olea-Martinez JM, et al. Hybrid natural orifice transluminal endoscopic cholecystectomy: prospective human series. Surg Endosc. 2011;25:19-22.

20. Autorino R, Yakoubi R, White WM, et al. Natural orifice transluminal endoscopic surgery (NOTES): Where are we going? A bibliometric assessment. BJU Int. 2013;111:11-6.

21. van den Boezem PB, Velthuis S, Lourens HJ, Samlal RA, Cuesta MA, Sietses C. Hybrid transvaginal cholecystectomy, clinical results and patient-reported outcomes of 50 consecutive cases. J Gastrointest Surg. 2013;17:907-12.

22. - Nijhawan S, Barajas-Gamboa JS, Majid S, et al. NOTES transvaginal hybrid cholecystectomy: the United States human experience. Surg Endosc. 2013;27:514-7. This cohort presents the largest experience on NOTES Cholecystectomies in the US.

23. Bulian DR, Trump L, Knuth J, et al. Less pain after transvaginal/ transumbilical cholecystectomy than after the classical laparoscopic technique: short-term results of a matched-cohort study. Surg Endosc. 2013;27:580-6.

24. Pollard JS, Fung AK, Ahmed I. Are natural orifice transluminal endoscopic surgery and single-incision surgery viable techniques for cholecystectomy? J Laparoendosc Adv Surg Tech A. 2012;22:1-14.

25. Gumbs AA, Fowler D, Milone L, et al. Transvaginal natural orifice translumenal endoscopic surgery cholecystectomy: early evolution of the technique. Ann Surg. 2009;249:908-12.

26. Nakajima K, Souma Y, Takahashi T, et al. Anatomical measurements to optimize instrumentation for transvaginal surgery. Surg Endosc. 2013;27:2052-7.

27. Delvaux G, Devroey P, De Waele B, Willems G. Transvaginal removal of gallbladders with large stones after laparoscopic cholecystectomy. Surg Laparosc Endosc 1993;3:307-9.

28. Marescaux J, Dallemagne B, Perretta S, Wattiez A, Mutter D, Coumaros D. Surgery without scars: report of transluminal cholecystectomy in a human being. Arch Surg. 2007;142:823-6 discussion 6-7.

29. Barajas-Gamboa JS, Coker AM, Cheverie J, et al. Trans-vaginal organ extraction: potential for broad clinical application. Surg Endosc. 2013;27(S1):281.

30. Wood SG, Panait L, Duffy AJ, Bell RL, Roberts KE. Complications of transvaginal natural orifice transluminal endoscopic surgery: A series of 102 patients. Ann Surg. 2013.

31. Kobiela J, Stefaniak T, Dobrowolski S, Makarewicz W, Lachinski AJ, Sledzinski Z. Transvaginal NOTES cholecystectomy in my partner? No way! Wideochirurgia i inne techniki malo inwazyjne. 2011;6:236-41.

32. Kim MC, Kim KH, Jang JS, Kwon HC, Kim BG, Rattner DW. Patient perception of natural orifice transluminal endoscopic surgery in an endoscopy screening program in Korea. Yonsei Med J. 2012;53:960-7.

33. Linke GR, Tarantino I, Bruderer T, et al. Transvaginal access for NOTES: a cohort study of microbiological colonization and contamination. Endoscopy. 2012;44:684-9.

34. • Linke GR, Luz S, Janczak J, et al. Evaluation of sexual function in sexually active women 1 year after transvaginal NOTES: a prospective cohort study of 106 patients. Langenbecks Arch Surg. 2013;398:139-45. This study has the largest sample size evaluating sexual function on transvaginal NOTES.

35. Borchert D, Federlein M, Ruckbeil O, Burghardt J, Fritze F, Gellert K. Prospective evaluation of transvaginal assisted cholecystectomy. Surg Endosc. 2012;26:3597-604.

36. Moris DN, Bramis KJ, Mantonakis EI, Papalampros EL, Petrou AS, Papalampros AE. Surgery via natural orifices in human beings: yesterday, today, tomorrow. Am J Surg. 2012;204: 93-102.

37. Hensel M, Schernikau U, Schmidt A, Arlt G. Surgical outcome and midterm follow-up after transvaginal NOTES hybrid cholecystectomy: analysis of a prospective clinical series. J Laparoendosc Adv Surg Tech A. 2011;21:101-6.

38. •• Rattner DW, Hawes R, Schwaitzberg S, Kochman M, Swanstrom L. The Second SAGES/ASGE White Paper on natural orifice transluminal endoscopic surgery: 5 years of progress. Surg Endosc. 2011;25:2441-8. This publication presents the SAGES/ASGE guidelines for the clinical application of NOTES procedures.

39. Horgan S, Meireles OR, Jacobsen GR, et al. Broad clinical utilization of NOTES: Is it safe? Surg Endosc. 2013;27:1872-80.

40. Arezzo A, Zornig C, Mofid H, et al. The EURO-NOTES clinical registry for natural orifice transluminal endoscopic surgery: a 2-year activity report. Surg Endosc. 2013;27(9):3073-84.

41. Mofid H, Emmermann A, Alm M, von Waldenfels HA, Felixmuller C, Zornig C. Is the transvaginal route appropriate for intraabdominal NOTES procedures? Experience and follow-up of 222 cases. Surg Endosc. 2013;27(8):2807-12.

42. Noguera JF, Cuadrado A, Dolz C, Olea JM, Garcia JC. Prospective randomized clinical trial comparing laparoscopic cholecystectomy and hybrid natural orifice transluminal endoscopic surgery (NOTES) (NCT00835250). Surg Endosc. 2012;26: $3435-41$. 